\title{
The food pattern in geographical relation to the risk of multiple sclerosis in the Mediterranean and Near East region
}

Since numerous investigations point to a cooperation of genetic and environmental factors in the aetiology of multiple sclerosis, epidemiological research is permanently challenged to identify putative risk factors and to generate new hypotheses. A prominent part of the human environment, when both frequency and intensity of contact are considered, is nutrition, which comprises numerous microbial (including viral) agents and immunologically and metabolically active compounds. Since multiple sclerosis has many characteristics of an autoimmune disorder, the fact that the gut associated immune system (GALT) is the most extended compartmentalised immunological organ $^{1}$ also justifies further attempts to identify putative risk factors in that special field by epidemiological means.

In ecological studies, a number of nutritional factors, mostly of animal origin and related to both meat $^{2-7}$ and milk $^{8}$ in particular, were suggested as mutiple sclerosis related, whereas case-control investigations did not confirm these hypotheses; $;^{9-13}$ however, the low validity of that approach and the special value of ecological studies in the search for dietary risk factors have been emphasised. ${ }^{14}$

The remarkable geographic pattern of multiple sclerosis in the Mediterranean and Near East region offers special opportunities both to test these earlier views and to generate new hypotheses. Whereas more recent studies had revealed high to medium range prevalence rates $\left(>20\right.$ per 100000 ) in southern Europe, ${ }^{15} 16$ in Israel, ${ }^{17}$ and in both population groups of Cyprus, ${ }^{18}$ low rates $(\leqslant 10$ per 100000 ) were found in Libya, ${ }^{19}$ Tunisia, ${ }^{20}$ Saudi Arabia, ${ }^{21}$ and among native Kuwaitis, ${ }^{22}$ although the methods of assessment varied in these developing countries. A particularly impressive finding was the steep gradient of the multiple sclerosis prevalence between Sicily (30-60 per 100000$)$ and Malta (4 per 100000$).^{23}$

In a comprehensive list edited by the Food and Agriculture Organisation (FAO) of the United Nations, ${ }^{24}$ the annual per caput intake of a variety of nutrients between 1962 and 1977 and of numerous individual food commodities between 1975 and 1977 is presented for many countries. These data were used for comparative evaluation of six countries at high/medium risk for multiple sclerosis (Italy, Spain, Yugoslavia, Greece, Cyprus, Israel) and four at low risk (Malta,
Tunisia, Libya, Saudia Arabia). Sixteen nutrients and 76 commodities from the FAO list were compared between both groups of countries by means of the Mann-Whitney U test. In addition, information on the habit of smoking for food preservation ${ }^{56}$ was sought in numerous works on ethnology, agriculture, and culinary arts, and in encyclopaedias from the countries or regions, respectively, under study; the practice of smoking was tested as a categorical variable by the Fisher test and by $\chi^{2}$ analysis between high/medium risk and low risk countries. Those items that reached the admitted level of statistical significance $(p=0 \cdot 1)$ were further tested for compatibility with the multiple sclerosis distribution both worldwide and within Europe. The list of high/ medium risk countries was then extended by the addition of the United Kingdom, France, Switzerland, Norway, Denmark, West Germany, Poland, and Hungary, and that of the low risk countries by Japan, Korea, and Malaysia (total 21 countries), using published multiple sclerosis data. All food items that showed a significant association with multiple sclerosis ( $U$ test; $p=0.05)$ at this step were further tested between six northern/central European high risk countries (the United Kingdom, Norway, Sweden, Denmark, Finland, West Germany) and five Mediterranean medium risk countries (Italy, Spain, Greece, Yugoslavia, Portugal) making allowance for remaining differences in multiple sclerosis prevalence between northern and southern Europe ${ }^{16}$ ( $U$ test; $p=0 \cdot 1$ ).

In the table, those food items are listed that met the criteria of a significant association with multiple sclerosis in all three tests along with the exact consumption data from Italy and Malta. As the result of this stepwise exclusion procedure, comparatively few factors remained compatible with the multiple sclerosis epidemiology in more general terms, although a great number of nutrients and commodities were originally associated in the Mediterranean/Near East region (eg, different nuts, many fruits, some vegetables such as potatoes and beans) (data not shown). It must be mentioned, however, that any type of dairy food, animal fat as such or specific animal fat products (lard, butter), wheat and oat products, and offals (as a surrogate marker for animal brain) were not significantly associated with multiple sclerosis in the region of main interest, and that distilled alcohol consumption was not in agreement with the worldwide pattern of multiple 
sclerosis. From the nine items that were associated with multiple sclerosis in all three tests (table), only "coffee", "margarine", and "smoke preservation" were in agreement with the multiple sclerosis gradient between Italy and Malta. The latter factor was strongly associated with multiple sclerosis in the Mediterranean/ Near East region and worldwide, but showed per se no clear variation between northern and southern Europe. When, however, quantitative data are taken into account, and a combined factor "smoked meat" or "smoked pork" is formed, the association is very high throughout. This factor is also compatible with the high risk of multiple sclerosis in Scotland and particularly in the Orkney and Shetland Islands and with the only transitorily high incidence in the Faroe Islands, ${ }^{5}$ whereas coffee can hardly explain both epidemiological features.

Arguments for the biological plausibility of some agents occurring in smoked and cured meat (in particular nitrophenol haptens and their protein conjugates) have been put forward. ${ }^{25}$ There appears at present to be no plausibility for the factor "margarine", which was also not compatible with the temporal pattern of multiple sclerosis in the Faroe Islands. ${ }^{5}$ Nevertheless, it seems justified to test all these variables (table) in case-control investigations, which should be restricted to younger multiple sclerosis patients having a relapsing-remitting course and include the parents in each case.

KLAUS LAUER

Department of Neurology Academic Teaching Hospital Heidelberger Landstr 379 D-6100 Darmstadt

Germany

Levels of significance ( $p$, Mann-Whitney $U$ test) reached by the food items associated with the multiple sclerosis (MS) prevalence in the Mediterranean/Near East region (Test $A ; p \leqslant 0 \cdot 1)$, in a worldwide comparison covering 21 countries (Test $B)$, and in a third comparison covering six northern/central and five southern European countries (Test C). Data on per caput consumption in Italy and Malta are also given, along with final compatibility with MS considering all comparisons.

\begin{tabular}{|c|c|c|c|c|c|c|}
\hline Commodity/nutrient & $\begin{array}{l}\text { Test } A \\
(p)\end{array}$ & $\begin{array}{l}\text { Test } B \\
(p)\end{array}$ & $\begin{array}{l}\text { Test } C \\
(p)\end{array}$ & Italy & Malta & $\begin{array}{l}\text { Final } \\
\text { compatibility } \\
\text { with } M S\end{array}$ \\
\hline Animal protein $(\mathrm{g} / \mathrm{d})$ & 0.05 & 0.002 & 0.01 & $40 \cdot 5$ & 39.9 & - \\
\hline Total fat $(\mathrm{g} / \mathrm{d})$ & 0.05 & 0.002 & 0.01 & 117 & 97 & - \\
\hline Calcium (mg/d) & $0 \cdot 1$ & 0.05 & 0.02 & 747 & 735 & - \\
\hline Riboflavin (mg/d) & $0 \cdot 1$ & 0.002 & 0.01 & 1.47 & 1.50 & - \\
\hline Pork (kg/year) & 0.05 & 0.002 & $0 \cdot 1$ & 15.9 & $12 \cdot 1$ & - \\
\hline Total meat ${ }^{\star}(\mathrm{kg} /$ year $)$ & $0 \cdot 1$ & 0.002 & 0.01 & $40 \cdot 6$ & $30 \cdot 0$ & - \\
\hline Margarine (kg/year) & $0 \cdot 1$ & 0.01 & 0.01 & 1.2 & 0.6 & + \\
\hline Coffee $(\mathrm{kg} /$ year $)$ & 0.01 & 0.002 & 0.05 & 2.8 & 0.9 & + \\
\hline Beer (kg/year) & $0 \cdot 1$ & 0.02 & 0.01 & $13 \cdot 6$ & $31 \cdot 6$ & - \\
\hline $\begin{array}{l}\text { Smoke preservation } \\
\text { (yes/no) }\end{array}$ & 0.01 & 0.001 & NS & yes & no & + \\
\hline
\end{tabular}

This work was supported by the Hertie Foundation, Frankfurt (Germany)

1 Brandtzaeg P, Valnes K, Scott H, Rognum TO, Bjerke K, Baklien $\mathrm{K}$. The human gastrointestinal immune system in health and disease. Scand $\mathcal{f}$ Gastroenterol 198520 (suppl 114): 17-38.

2 Alter $M$, Yamoor $M$, Harshe $M$. Multiple sclerosis and nutrition. Arch Neurol 1974; 31: 267-72.

3 Swank R, Lerstad O, Ström A, Backer J. Multiple sclerosis in rural Norway. $N$ Engl 7 Med 1952; 246: 721-8.

4 Nanji AA, Narod S. Multiple sclerosis, latitude and dietary fat: is pork the missing link? Med Hypotheses 1986; 20 279-82.

5 Lauer K. Dietary changes in relation to multiple sclerosis in the Faroe Islands: an evaluation of literary sources. Neuroepidemiology 1989; 8: 200-6.

6 Lauer K. Multiple sclerosis in relation to meat preservation in France and Switzerland. Neuroepidemiology 1989; 8 308-15.

7 Lauer K. Sociogeographic variables in relation to the risk of multiple sclerosis in the USA (abstract). $\mathcal{F}$ Neurol 1990; 237 (suppl 1): 102

8 Agranoff BWA, Goldberg D. Diet and the geographical distribution of multiple sclerosis. Lancet 1974; ii: 1061-6.

9 Butcher PJ. Milk consumption and multiple sclerosis-an etiological hypothesis. Med Hypotheses 1986; 19: 169-78.

10 Antonovsky A, Leibowitz U, Smith HA et al. Epidemiological study of multiple sclerosis in Israel. I. An overall review of methods and findings. Arch Neurol 1965 13: 183-93.

11 Poskanzer DC, Sheridan JL, Prenney LB, Walker AM Multiple sclerosis in the Orkneys and Shetland Islands. II. The search for an exogenous etiology. $f$ Epidemiol Community Health 1980; 34: 240-52.

12 Cendrowski W, Wender M, Dominik W, Flejsierowicz Z Owsianowski M, Popiel M. Epidemiological study of multiple sclerosis in Western Poland. Eur Neurol 1969; 2 90-108.

13 Warren SA, Warren KG, Greenhill S, Paterson M. How multiple sclerosis is related to animal illness, stress and diabetes. Can Med Assoc ₹ 1982; 126: 377-85.

14 Wynder EL, Shigematsu T. Environmental factors of cancer of the colon and rectum. Cancer 1967; 20: 1520-61.

15 Battaglia MA. Multiple sclerosis epidemiology in Europe In: Battaglia MA, Crimi G, eds. An update on multiple sclerosis. Bologna: Monduzzi, 1989: 201-8.

16 Bauer H. Symposium report: multiple sclerosis in Europe. $\tilde{J}$ Neurol 1988; 234: 195-205.

17 Alter M, Kahana E, Loewenson R. Migration and risk of multiple sclerosis. Neurology 1978; 28: 1089-93.

18 Middleton LT, Dean G. Multiple sclerosis in Cyprus (abstract). $\mathcal{F}$ Neurol 1990; 237 (suppl 1): 102.

19 Radhakrishnan A, Ashok PP, Sridharan R, Mousa ME Prevalence and pattern of multiple sclerosis in Benghazi, north-eastern Libya. $\mathcal{F}$ Neurol Sci 1985; 70: 39-46.

20 Kurtzke JF. Geographic distribution of multiple sclerosis an update with special reference to Europe and the Mediterranean region. Act Neurol Scand 1980; 62: 65-80.

21 Yaqub BA, Daif AK. Multiple sclerosis in Saudi Arabia. Neurol 1988; 38: 621-3.

22 Naiim Al-Din AS, Khogali $M$, Poser CM, et al. Epidemiology of multiple sclerosis in Arabs in Kuwait: a comparative study between Kuwaitis and Palestinians. $\mathcal{f}$ Neurol Sci 1990; 100: 137-41.

23 Vassallo L, Elian M, Dean G. Multiple sclerosis in southern Europe. II. Prevalence in Malta in 1978. F Epidemio Community Health 1979; 33: 111-3.

24 Food and Agriculture Organisation (FAO) of the United Nations. Food balance sheets 1975-77 average and per caput food supplies 1961-1965 average, 1967-1977. Rome: FAO, 1980.

25 Lauer K. Environmental nitrophenols and autoimmunity (letter). Mol Immunol 1990; 27: 697-8. 